\title{
Anorexigenic peptide (leptin, obestatin, nesfatin-1) levels and their impact on assisted reproductive technology treatment outcomes in patients with polycystic ovary syndrome
}

\author{
Bulut Varlı ', Yavuz Emre Şükürr , Batuhan Özmen ${ }^{1}$, Berrin İmge Ergüder ${ }^{2}$, Murat Sönmezer ${ }^{1}$, Bülent Berker ${ }^{1}$, \\ Cem Atabekoğlu', Ruşen Aytaç ${ }^{1}$ \\ Departments of 'Obstetrics and Gynecology and ${ }^{2}$ Biochemistry, Faculty of Medicine, Ankara University, Ankara, Turkey
}

Objective: In this study we aimed to assess anorexigenic peptide levels in patients with or without polycystic ovary syndrome (PCOS) and their effects on assisted reproductive treatment (ART) outcomes.

Methods: A prospective case-control study was conducted in a tertiary care university-based ART clinic. Eighty-three patients were included in the study. The PCOS group included 41 patients, and the non-PCOS group included 42 controls. The 2003 Rotterdam criteria were used for PCOS patient selection. The ART indications in the non-PCOS group were tubal factor or unexplained infertility. Venous blood samples were taken on the third day of the menstrual cycle to determine the serum anorexigenic peptide levels. The enzyme-linked immunosorbent assay method was used for laboratory analyses.

Results: In the PCOS group, serum obestatin levels were significantly lower than in the control group, but serum anorexigenic peptide levels were similar in PCOS patients with or without clinical pregnancy. Ovarian hyperstimulation syndrome (OHSS) was diagnosed only in PCOS patients, and the obestatin levels of OHSS patients were significantly lower than those of other PCOS patients.

Conclusion: Baseline anorexigenic peptide levels did not affect the clinical pregnancy rate in ART cycles. Obestatin may play a role in the pathophysiology of OHSS. This possibility should be confirmed in further research.

Keywords: Assisted reproductive technique; Leptin; Nesfatin; Obestatin; Polycystic ovary syndrome

Received: February 15 · Revised: July 28, 2021 · Accepted: July 28, 2021

Corresponding author: Bulut Varlı

Department of Obstetrics and Gynecology, Faculty of Medicine, Ankara University, Kadın Hastalıkları ve Doğum A.B.D. 06590 Dikimevi, Ankara, Turkey Tel: +90-53-2320-6892 Fax: +90-31-2320-3553 E-mail: bulutvarli@gmail.com

*This study was supported by Ankara University Scientific Research Project Coordination Unit (Project No.15H0230006).

*This study was presented as an oral presentation at the 26th European Congress of the European Board \& College of Obstetrics and Gynecology on March 8-10, 2018, in Paris, France

This is an Open Access article distributed under the terms of the Creative Commons Attribution Non-Commercial License (http://creativecommons.org/licenses/by-nc/4.0/) which permits unrestricted non-commercial use, distribution, and reproduction in any medium, provided the original work is properly cited.

\section{Introduction}

Polycystic ovary syndrome (PCOS) is a complex clinical and biochemical condition with signs of ovulatory dysfunction and/or hyperandrogenism during adolescence, followed by infertility due to anovulation. Approximately $5 \%$ to $10 \%$ of reproductive-age women have been diagnosed with PCOS [1]. Stein and Leventhal defined PCOS in 1935; thousands of articles on PCOS are now published annually, but the exact mechanism of the syndrome remains unknown.

Brain and peripheral tissues control reproductive function [2], and anorexigenic peptides provide communication between these two systems [3]. Leptin, obestatin, and nesfatin-1 are examples of anorexigenic peptides that may have a relationship with PCOS pathophysiology $[4,5]$. Leptin is an important peptide for signal transmis- 
sion between the adipose tissue and the reproductive system [5]. The true effect of PCOS on serum leptin levels is unknown, as some researchers found no difference and others found higher leptin levels in PCOS patients than in healthy controls $[3,6]$. The granulosa and theca cells of ovarian follicles have leptin receptors, and elevated leptin levels can affect follicular growth [7]. Obestatin, a newly discovered hormone, is mainly synthesized by gastrointestinal organs [8]. Reductions in appetite and nutrient intake are its most prominent physiological effects [9]. However, the effects of obestatin on reproductive physiology are being investigated, and its exact role in PCOS pathophysiology is not known [10]. The central nervous system, especially the hypothalamus, is the primary source of nesfatin-1 [11], although insulin-synthesizing pancreatic beta-cells also synthesize nesfatin-1. As a result of interactions with pancreatic beta-cells, nesfatin-1 may play an important role in the regulation of insulin production [12]. As is the case with obestatin, firm conclusions about the effect of PCOS on serum nesfatin-1 levels are not possible because the results of studies comparing PCOS subjects with controls are scarce $[4,13]$.

In light of the inconsistent results that have been reported on this topic, we aimed to assess serum anorexigenic peptide levels in patients with PCOS in this study and to determine their effects on assisted reproductive treatment (ART) treatment outcomes.

\section{Methods}

A case-control study was conducted among couples with primary infertility who were admitted for an ART cycle at the outpatient infertility center of our department. The study was conducted between March 2016 and December 2016. The patients were informed about the study protocol and all participants provided written informed consent. The local ethical committee of Ankara University School of Medicine approved the study protocol (No. 11-456-15). The Code of Ethics of the World Medical Association (Declaration of Helsinki) was carefully followed throughout the entire study period.

The inclusion criteria for the study were an age between 18 and 40 years, as well as a baseline follicle-stimulating hormone level between 3 and $12 \mathrm{IU} / \mathrm{L}$. The exclusion criteria were a history of bariatric surgery, diagnosis of endometriosis with laparoscopy, a history of ovarian surgery, a chromosomal abnormality in the female partner, endocrine disorders related to female infertility, and male factor infertility. The case group comprised patients who were diagnosed with PCOS according to the Rotterdam criteria [14] and scheduled for an ART cycle. The control group consisted of patients who were scheduled for ART either due to tubal factor infertility or unexplained infertility.

Recombinant follicle-stimulating hormone (Gonal-F, Merck-Sero- no, Istanbul, Turkey) was started after venous blood sampling to determine serum anorexigenic peptide levels. Gonadotropin dose adjustment was done according to age, body mass index (BMI), and the results of ovarian reserve tests. A gonadotropin-releasing hormone antagonist (Cetrotide, Merck-Serono) was generally added to the ovarian stimulation protocol $(0.25 \mathrm{mg} /$ day) on the sixth day of stimulation or when the leading follicle was $>13 \mathrm{~mm}$. When at least 3 follicles were $\geq 18 \mathrm{~mm}$, final oocyte triggering was performed with a subcutaneous injection of $250 \mathrm{mg}$ of recombinant human chorionic gonadotropin (Ovitrelle, Merck-Serono). Oocyte pick-up was performed under transvaginal ultrasound guidance 35-36 hours after the final oocyte trigger. All embryo transfers were performed with day 3 embryos. The number of transferred embryos was in accordance with national embryo transfer regulations. The luteal phase was supported with vaginal micronized progesterone $(90 \mathrm{mg} / \mathrm{day}$, Crinone 8\% gel; Merck-Serono).

Clinical pregnancy was defined as the presence of an intrauterine fetal heartbeat at 6 gestational weeks. The implantation rate was calculated separately for each woman as the number of gestational sacs divided by the transferred embryos, multiplied by 100 . The live birth rate was the primary outcome measure. Peripheral blood samples were obtained from the brachial vein after overnight fasting on day 3 of the menstrual cycle to determine serum anorexigenic peptide levels. Blood samples were drawn into tubes containing ethylene-diamine-tetraacetic acid (EDTA) $2 \mathrm{Na}(1 \mathrm{mg} / \mathrm{mL}$ ) and aprotinin $(500 \mathrm{U} / \mathrm{mL})$. Samples were immediately centrifuged at $3000 \times g$ for 10 minutes at $4^{\circ} \mathrm{C}$ and then stored at $-80^{\circ} \mathrm{C}$ until the day when enzyme-linked immunosorbent assay (ELISA) was performed. Serum leptin, obestatin, and nesfatin-1 analyses were done with commercial ELISA kits (DIAsource Leptin ELISA Kit [sensitivity, $0.1 \mathrm{ng} / \mathrm{mL}$; intra-assay coefficient of variability [CV], <13.3\%; inter-assay CV, $<10.2 \%$; KAP2281, Belgium; SunRed Biotechnology human obestatin ELISA kit [sensitivity, 0.1 pg/mL; intra-assay CV, < 10\%; inter-assay CV, < 15\%], 201-12-0971, China; and SunRed Biotechnology Human Nestatin-1 ELISA kit [sensitivity, $0.113 \mathrm{mmol} / \mathrm{L}$; intra-assay CV, < 10\%; inter-assay CV, < 12\%], 201-12-4341, China).

SPSS ver. 15.0 (SPSS Inc., Chicago, IL, USA) was used for data analysis. The Kolmogorov-Smirnov test was performed to test the normality of the distribution of the variables. According to distribution of each variable, either the Student $t$-test or the Mann-Whitney $U$-test was calculated. Categorical variables were compared using the chisquare test. A $p$-value of $<0.05$ was considered to indicate statistical significance.

\section{Results}

In the final analysis, 83 patients were eligible for the study. The 
study group included 41 patients with PCOS and the control group included 42 patients with either tubal factor infertility or unexplained infertility. The groups were similar in terms of baseline and demographic parameters except for baseline luteinizing hormone (LH) levels (Table 1). The features of the ovarian stimulation cycles are presented in Table 1. The clinical pregnancy rate per embryo transfer was comparable between the PCOS (35.1\%) and control (35.7\%) groups.

Table 1 also presents the serum anorexigenic peptide levels of both groups. The obestatin concentration was found to be significantly lower in the PCOS group (169.02 pg/mL; range, 15.42-358.98 $\mathrm{pg} / \mathrm{mL}$ ) than in the control group $(224.51 \mathrm{pg} / \mathrm{mL}$; range, 22.20 $437.79 \mathrm{pg} / \mathrm{mL})(p=0.04)$. The median serum leptin concentrations in the PCOS and control groups were $26.15 \mathrm{ng} / \mathrm{mL}$ (range, 4.60-88.50 $\mathrm{ng} / \mathrm{mL}$ ) and $27.20 \mathrm{ng} / \mathrm{mL}$ (range, $1.90-122.90 \mathrm{ng} / \mathrm{mL}$ ), respectively $(p=0.530)$. The nesfatin- 1 concentrations in the PCOS and control groups were $100.47 \mathrm{mmol} / \mathrm{L}$ (range, 13.70-411.51 mmol/L) and $144.35 \mathrm{mmol} / \mathrm{L}$ (range, $26.99-450.82 \mathrm{mmol} / \mathrm{L}$ ), respectively $(p=0.096)$.

Additionally, anorexigenic peptide levels were similar in PCOS patients with and without clinical pregnancy (Table 2). The mean levels of leptin, nesfatin-1, and obestatin in patients with clinical pregnancy were $21.21 \pm 12.74 \mathrm{ng} / \mathrm{mL}, 96.89 \pm 72.49 \mathrm{mmol} / \mathrm{L}$, and $136.97 \pm 86.92$ $\mathrm{pg} / \mathrm{mL}$, respectively. The mean levels of leptin, nesfatin-1, and obestatin in patients without clinical pregnancy were $27.25 \pm 17.71 \mathrm{ng} / \mathrm{mL}$, $77.50 \pm 66.08 \mathrm{mmol} / \mathrm{L}$, and $188.51 \pm 110.05 \mathrm{pg} / \mathrm{mL}$, respectively.

In the PCOS group, 4 embryo transfers were postponed due to the development of early ovarian hyperstimulation syndrome (OHSS). The mean obestatin level was significantly lower in patients who had both PCOS and OHSS than in patients with only PCOS $(93.68 \pm 49.33$ $\mathrm{pg} / \mathrm{mL}$ vs. $169.97 \pm 98.33 \mathrm{pg} / \mathrm{mL}, p=0.04)$. However, the limited number of patients with OHSS limited the statistical power. We also

Table 1. Demographic characteristics and baseline variables of the study population

\begin{tabular}{|c|c|c|c|}
\hline Variable & Control $(n=42)$ & $\operatorname{PCOS}(n=41)$ & $p$-value \\
\hline Age (yr) & $29.0 \pm 3.7$ & $27.7 \pm 3.6$ & 0.690 \\
\hline $\mathrm{BMI}\left(\mathrm{kg} / \mathrm{m}^{2}\right)$ & $23.7 \pm 5.0$ & $24.8 \pm 4.2$ & 0.552 \\
\hline Duration of infertility (yr) & $6.5 \pm 4.6$ & $5.0 \pm 3.2$ & 0.100 \\
\hline $\mathrm{FSH}(\mathrm{mlU} / \mathrm{mL})$ & $7.4 \pm 3.2$ & $6.2 \pm 2.0$ & 0.462 \\
\hline $\mathrm{LH}(\mathrm{mlU} / \mathrm{mL})$ & $4.5 \pm 2.1$ & $7.5 \pm 4.8$ & 0.008 \\
\hline Duration of ovarian stimulation (day) & $9.9 \pm 1.9$ & $10.4 \pm 2.2$ & 0.191 \\
\hline Total dose of gonadotropins (IU) & $2,689 \pm 871$ & $2,351 \pm 735$ & 0.254 \\
\hline Maximum E2 concentration (pg/mL) & $2,304 \pm 1,628$ & $2,977 \pm 1,821$ & 0.197 \\
\hline No. of follicles $\geq 17 \mathrm{~mm}$ on day of hCG & $3.4 \pm 2.0$ & $5.3 \pm 3.0$ & 0.114 \\
\hline Endometrial thickness on day of $\mathrm{hCG}(\mathrm{mm})$ & $10.0 \pm 2.0$ & $10.0 \pm 3.1$ & 0.326 \\
\hline No. of oocytes retrieved & $7.2 \pm 3.7$ & $12.4 \pm 6.2$ & 0.002 \\
\hline No. of Mll oocytes & $6.5 \pm 3.9$ & $11.1 \pm 5.2$ & 0.005 \\
\hline Fertilization rate $(\%)$ & $63.6 \pm 30.4$ & $68.1 \pm 25.9$ & 0.234 \\
\hline No. of day 3 grade $A$ embryos & $4.0 \pm 2.5$ & $7.9 \pm 2.9$ & 0.006 \\
\hline Clinical pregnancy rate & $15(35.7)$ & $13(35.1)$ & 0.950 \\
\hline OHSS & 0 & $4(9.52)$ & 0.040 \\
\hline Leptin (ng/mL) & $27.20(1.90-122.90)$ & $26.15(4.60-88.50)$ & 0.530 \\
\hline Nesfatin-1 (mmol/L) & $144.35(26.99-450.82)$ & $100.47(13.70-411.51)$ & 0.096 \\
\hline Obestatin (pg/mL) & $224.51(22.20-437.79)$ & $169.02(15.40-358.98)$ & 0.040 \\
\hline
\end{tabular}

Values are presented as mean \pm standard deviation, number (\%), or median (range).

PCOS, polycystic ovary syndrome; BMI, body mass index; FSH, follicle-stimulating hormone; LH, luteinizing hormone; E2, estradiol; hCG, human chorionic gonadotropin; MII, metaphase II; OHSS, ovarian hyperstimulation syndrome.

Table 2. Anorexigenic peptide levels in PCOS patients with and without clinical pregnancy

\begin{tabular}{lccc}
\hline Variable & Clinical pregnancy $(+)(\mathrm{n}=13)$ & Clinical pregnancy $(-)(\mathrm{n}=28)$ & $p$-value \\
\hline Leptin $(\mathrm{ng} / \mathrm{mL})$ & $21.21 \pm 12.74$ & $27.25 \pm 17.71$ & 0.458 \\
Nesfatin-1 $(\mathrm{mmol} / \mathrm{L})$ & $96.89 \pm 72.49$ & $77.50 \pm 66.08$ & 0.601 \\
Obestatin $(\mathrm{pg} / \mathrm{mL})$ & $136.97 \pm 86.92$ & $188.51 \pm 110.05$ & 0.328 \\
\hline
\end{tabular}

Values are presented as mean \pm standard deviation.

PCOS, polycystic ovary syndrome. 
compared the baseline and ovarian stimulation characteristics of these patients with OHSS-free PCOS patients, as shown in Table 3, and BMI was the only factor that showed a significant difference between these groups $\left(21.7 \pm 1.2 \mathrm{~kg} / \mathrm{m}^{2}\right.$ vs. $\left.26.4 \pm 5.5 \mathrm{~kg} / \mathrm{m}^{2}, p=0.005\right)$.

\section{Discussion}

In this study, we aimed to assess the levels of anorexigenic peptides in patients with PCOS and their effects on ART outcomes. In PCOS patients, only obestatin levels were found to be significantly lower than in controls. Baseline anorexigenic peptide levels did not show any effect on ART outcomes in our study. The most interesting finding of the study may have been that, in the PCOS group, four patients were diagnosed with early OHSS, and their baseline serum obestatin levels were significantly lower than the rest of the PCOS group.

The hormones secreted by the gastrointestinal system and the adipose tissue play important roles in the management of the reproductive axis via autocrine, paracrine, and endocrine effects. Recently, Comninos et al. [2] reviewed the effects of seven gastrointestinal system-derived hormones and five adipose tissue-derived hormones on the reproductive system. According to them, these hormones can be used exogenously to solve reproductive problems.

Leptin is the most investigated anorexigenic peptide in the literature. In our study, no significant difference in serum leptin levels was found between patients with PCOS and the control group. This finding is also supported by other studies $[3,15]$. The effects of leptin on ART outcomes are unclear. High leptin levels can increase the oocyte maturation and fertilization rates, but can also affect the pregnancy rate negatively. High leptin levels can cause intra-follicular hypoxia due to the suppression of steroidogenesis [16-18]. In support of the latter findings, women with low leptin levels have been reported to have better ART outcomes [19,20]. In our study, although we found lower leptin levels in women who achieved clinical pregnancy, the difference was statistically insignificant between groups.

Vascular endothelial growth factor (VEGF) is an important mediator in the pathogenesis of OHSS. Leptin levels showed positive correlations with follicular-fluid VEGF levels in previous studies, but 2 studies did not show any difference in baseline serum leptin levels between patients who did and did not develop OHSS [21,22]. Our findings are also similar to those. In the PCOS group, four patients were diagnosed with early OHSS. However, their baseline serum leptin levels were similar to those of the rest of the PCOS group

In animal studies, insulin-secreting beta-cells and cells secreting pro-nesfatin-1 (the precursor of nesfatin-1) were found in the same location in the pancreas [12]. Hyperinsulinemia is a common clinical finding in PCOS [13], and hyperinsulinemia can impair beta-cell function. As their location in the pancreas is the same, nesfatin-1 secretion might also be affected by hyperinsulinemia. This theory could explain the low nesfatin-1 levels in PCOS patients [23,24], which was also observed in our study. Considering the effects of nesfatin-1 on gonadotropin synthesis in the pituitary gland, a decrease in central nesfatin-1 levels may also increase serum LH levels in women with PCOS [25].

In a previous study, researchers evaluated the effect of nesfatin-1 levels on ART outcomes. No relationships were found between the fertilization rate, pregnancy rate, and nesfatin-1 levels. However, patients with higher intrafollicular fluid nesfatin-1 levels were found to have a higher number of oocytes and good-quality embryos available for cryopreservation [26]. In our study, we did not find a relationship between serum nesfatin-1 levels and the number of mature oocytes retrieved. However, we found higher serum nesfatin-1 levels in patients who achieved clinical pregnancy, but the difference was statistically insignificant. Larger studies, particularly focusing on his-

Table 3. Comparison of the demographic characteristics, ovarian reserve test results, cycle parameters, and anorexigenic peptide levels in PCOS patients who were diagnosed with OHSS

\begin{tabular}{lccc}
\hline Variable & OHSS $(+)(\mathrm{n}=4)$ & OHSS $(-)(\mathrm{n}=37)$ & $p$-value \\
\hline Age $(\mathrm{yr})$ & $28.8 \pm 2.6$ & $29.3 \pm 3.9$ & 0.769 \\
BMI $\left(\mathrm{kg} / \mathrm{m}^{2}\right)$ & $21.7 \pm 1.2$ & $26.4 \pm 5.5$ & 0.005 \\
FSH $(\mathrm{mlU} / \mathrm{mL})$ & $6.5 \pm 1.3$ & $7.3 \pm 2.4$ & 0.667 \\
LH $(\mathrm{mlU} / \mathrm{mL})$ & $10.3 \pm 3.1$ & $7 \pm 2.2$ & 0.262 \\
No. of antral follicle counts & $22.2 \pm 3.4$ & $19.5 \pm 2.8$ & 0.080 \\
Duration of ovarian stimulation (day) & $9.8 \pm 2.5$ & $10.6 \pm 2.2$ & 0.554 \\
Total dose of gonadotropins (IU) & $2,756 \pm 1,068$ & $2,313 \pm 617$ & 0.476 \\
Leptin $(\mathrm{ng} / \mathrm{mL})$ & $33.60(12-88.50)$ & $25.90(4.60-73.95)$ & 0.706 \\
Nesfatin-1 $(\mathrm{mmol} / \mathrm{L})$ & $55.95(30.41-101.23)$ & $106.60(13.70-451.11)$ & 0.133 \\
Obestatin $(\mathrm{pg} / \mathrm{mL})$ & $93.68(15.40-154.91)$ & $169.97(26.44-358.98)$ & 0.040
\end{tabular}

Values are presented as mean \pm standard deviation or median (range).

PCOS, polycystic ovary syndrome; OHSS, ovarian hyperstimulation syndrome; BMI, body mass index; FSH, follicle-stimulating hormone; LH, luteinizing hormone. 
tologic and embryologic follow-up, may clarify the possible effects of nesfatin-1 on ART outcomes.

Ghrelin, which was first discovered in 1999, affects luteal cell function by reducing progesterone synthesis and shifting the balance between luteotropic and luteolytic factors [27]. Obestatin, which has the same origin as ghrelin, antagonizes the effects of ghrelin [8]. Obestatin can have effects on ovarian remodeling. The first study evaluating the effects of obestatin on the reproductive system was reported in 2008. In that study, granulosa cells were exposed to obestatin, and levels of proliferation markers (cyclin B1, MAP kinase) and apoptotic peptides (BAX, caspase 3 ) increased in granulosa cells after obestatin exposure [28]. Low obestatin levels may play a role in the development of the ultrasonographic findings of PCOS by negatively affecting ovarian morphology and the ovarian microenvironment. In our study, patients with PCOS had significantly lower serum levels of obestatin than the control group.

OHSS is a dreaded possibility for clinicians dealing with ART, since it can cause life-threatening complications. In the PCOS group, basal obestatin levels in patients who developed OHSS were significantly lower than in those who did not. Romani et al. [29] reported that the exposure of luteal cells to obestatin reduced VEGF release, which is responsible for capillary permeability during OHSS. Obestatin may act as a protective agent against OHSS. Future studies with larger cohorts are urgently needed to clarify whether obestatin has a protective effect against OHSS.

The most important strength of our study was the systematic exploration of individual anorexigenic peptide parameters. In addition, to the best of our knowledge, this is the first study to show a significant association between decreased serum obestatin levels and OHSS. However, only four patients developed OHSS, which makes the statistical significance of the difference between groups questionable. Further studies are needed to clarify our findings.

The main limitation of this study is the lack of measurements of anorexigenic peptide levels in the follicular fluid and the fact that correlations between serum and follicular fluid levels were not determined. We measured serum anorexigenic peptide levels before commencing exogenous gonadotropins. These medications can alter serum anorexigenic peptide levels. If serum anorexigenic peptide level measurements were also done during the ovarian stimulation period, the effects of serum anorexigenic peptide levels could have been evaluated more precisely. This is another limitation of our study.

In conclusion, according to the results of our study, serum obestatin levels are significantly lower in patients with PCOS. However, neither obestatin nor the other anorexigenic peptides showed significant effects on ART outcomes. Furthermore, obestatin levels were significantly lower in PCOS patients who developed OHSS, suggesting a possible prophylactic effect of normal obestatin levels against OHSS.

\section{Conflict of interest}

No potential conflict of interest relevant to this article was reported.

\section{ORCID}

Bulut Varlı https://orcid.org/0000-0002-0941-2314

Yavuz Emre Şükür

Batuhan Özmen https://orcid.org/0000-0003-0815-3522 https://orcid.org/0000-0002-4504-669X Berrin İmge Ergüder Murat Sönmezer https://orcid.org/0000-0002-7945-3074 https://orcid.org/0000-0001-6101-1414

Bülent Berker

Cem Atabekoğlu

Ruşen Aytaç https://orcid.org/0000-0001-7346-7128 https://orcid.org/0000-0003-0264-0709 https://orcid.org/0000-0002-2644-545X

\section{Author contributions}

Conceptualization: BV, BÖ. Data curation: BV, YEŞ, BIE, MS, BB, CA, RA. Formal analysis: $B V, B O ̈$. Funding acquisition: $B V, B O ̈$. Methodology: BV, YEŞ, BÖ, BiE. Project administration: BV, BÖ, MS, BB, CA, RA. Visualization: $B V$, $Y E S$. Writing-original draft: $B V, Y E S ̧$. Writing-review \& editing: $B O ̈, M S, B B, C A, R A$.

\section{References}

1. Azziz R, Woods KS, Reyna R, Key TJ, Knochenhauer ES, Yildiz BO. The prevalence and features of the polycystic ovary syndrome in an unselected population. J Clin Endocrinol Metab 2004;89: 2745-9.

2. Comninos AN, Jayasena CN, Dhillo WS. The relationship between gut and adipose hormones, and reproduction. Hum Reprod Update 2014;20:153-74.

3. Telli MH, Yildirim M, Noyan V. Serum leptin levels in patients with polycystic ovary syndrome. Fertil Steril 2002;77:932-5.

4. Ademoglu EN, Gorar S, Carlioglu A, Yazici H, Dellal FD, Berberoglu $Z$, et al. Plasma nesfatin-1 levels are increased in patients with polycystic ovary syndrome. J Endocrinol Invest 2014;37:715-9.

5. Fernandez-Fernandez R, Martini AC, Navarro VM, Castellano JM, Dieguez C, Aguilar E, et al. Novel signals for the integration of energy balance and reproduction. Mol Cell Endocrinol 2006;254255:127-32.

6. Hahn S, Haselhorst U, Quadbeck B, Tan S, Kimmig R, Mann K, et al. Decreased soluble leptin receptor levels in women with polycystic ovary syndrome. Eur J Endocrinol 2006;154:287-94.

7. Cioffi JA, Van Blerkom J, Antczak M, Shafer A, Wittmer S, Snodgrass HR. The expression of leptin and its receptors in pre-ovula- 
tory human follicles. Mol Hum Reprod 1997;3:467-72.

8. Zhang JV, Ren PG, Avsian-Kretchmer O, Luo CW, Rauch R, Klein C, et al. Obestatin, a peptide encoded by the ghrelin gene, opposes ghrelin's effects on food intake. Science 2005;310:996-9.

9. Li JB, Asakawa A, Cheng K, Li Y, Chaolu H, Tsai M, et al. Biological effects of obestatin. Endocrine 2011;39:205-11.

10. Yildiz G, Yucel A, Noyan V, Bostanci MS, Sa soz N. Evaluation of effects of diet on serum obestatin levels in over-weight patients with polycystic ovary syndrome. J Obes Metab Res 2014;1:230-7.

11. Kohno D, Nakata M, Maejima Y, Shimizu H, Sedbazar U, Yoshida N, et al. Nesfatin-1 neurons in paraventricular and supraoptic nuclei of the rat hypothalamus coexpress oxytocin and vasopressin and are activated by refeeding. Endocrinology 2008;149:1295-301.

12. Gonzalez R, Tiwari A, Unniappan S. Pancreatic beta cells colocalize insulin and pronesfatin immunoreactivity in rodents. Biochem Biophys Res Commun 2009;381:643-8.

13. Deniz R, Gurates B, Aydin S, Celik H, Sahin I, Baykus Y, et al. Nesfatin-1 and other hormone alterations in polycystic ovary syndrome. Endocrine 2012;42:694-9.

14. Rotterdam ESHRE/ASRM-Sponsored PCOS Consensus Workshop Group. Revised 2003 consensus on diagnostic criteria and longterm health risks related to polycystic ovary syndrome. Fertil Steril 2004;81:19-25.

15. Plati E, Kouskouni E, Malamitsi-Puchner A, Boutsikou M, Kaparos G, Baka S. Visfatin and leptin levels in women with polycystic ovaries undergoing ovarian stimulation. Fertil Steril 2010;94:1451-6.

16. Craig J, Zhu H, Dyce PW, Petrik J, Li J. Leptin enhances oocyte nuclear and cytoplasmic maturation via the mitogen-activated protein kinase pathway. Endocrinology 2004;145:5355-63.

17. De Placido G, Alviggi C, Clarizia R, Mollo A, Alviggi E, Strina I, et al. Intra-follicular leptin concentration as a predictive factor for in vitro oocyte fertilization in assisted reproductive techniques. J Endocrinol Invest 2006;29:719-26.

18. Barroso G, Barrionuevo M, Rao P, Graham L, Danforth D, Huey S, et al. Vascular endothelial growth factor, nitric oxide, and leptin follicular fluid levels correlate negatively with embryo quality in IVF patients. Fertil Steril 1999;72:1024-6.

19. Mantzoros CS. Role of leptin in reproduction. Ann N Y Acad Sci
2000;900:174-83.

20. Gurbuz B, Yalti S, Ficicioglu C, Tasdemir S. The relation of serum and follicular fluid leptin and ovarian steroid levels in response to induction of ovulation in in vitro fertilization cycles. Eur J Obstet Gynecol Reprod Biol 2005;118:214-8.

21. Asimakopoulos B, Nikolettos N, Papachristou DN, Simopoulou M, Al-Hasani S, Diedrich K. Follicular fluid levels of vascular endothelial growth factor and leptin are associated with pregnancy outcome of normal women participating in intracytoplasmic sperm injection cycles. Physiol Res 2005;54:263-70.

22. Salamalekis E, Makrakis E, Vitoratos N, Chassiakos D, Baka S, Creatsas G. Insulin levels, insulin resistance, and leptin levels are not associated with the development of ovarian hyperstimulation syndrome. Fertil Steril 2004;82:244-6.

23. Taskin MI, Eser B, Adali E, Kara H, Cuce C, Hismiogulları AA. NUCB2 gene polymorphism and its relationship with nesfatin-1 levels in polycystic ovary syndrome. Gynecol Endocrinol 2016;32:46-50.

24. Alp E, Gormus U, Guducu N, Bozkurt S. Nesfatin-1 levels and metabolic markers in polycystic ovary syndrome. Gynecol Endocrinol 2015:31:543-7.

25. García-Galiano D, Navarro VM, Roa J, Ruiz-Pino F, Sanchez-Garrido MA, Pineda $R$, et al. The anorexigenic neuropeptide, nesfatin- 1 , is indispensable for normal puberty onset in the female rat. J Neurosci 2010;30:7783-92.

26. Lee SJ, Jung JY, An SJ, Lee K, Park JH, Yang HW. Nesfatin-1 level in follicular fluid (FF) is associated with the number of retrieved oocytes in IVF cycle. In: 31st Annual Meeting of ESHR; 2015; Lisbon, Portugal.

27. Tropea A, Tiberi F, Minici F, Orlando M, Gangale MF, Romani F, et al. Ghrelin affects the release of luteolytic and luteotropic factors in human luteal cells. J Clin Endocrinol Metab 2007;92:3239-45.

28. Meszarosova M, Sirotkin AV, Grossmann R, Darlak K, Valenzuela F. The effect of obestatin on porcine ovarian granulosa cells. Anim Reprod Sci 2008;108:196-207.

29. Romani F, Lanzone A, Tropea A, Familiari A, Scarinci E, Sali M, et al. In vitro effect of unacylated ghrelin and obestatin on human luteal cell function. Fertil Steril 2012;97:991-6. 